\title{
Mortality-related risk factors and long-term survival after 4460 liver resections in Sweden-a population-based study
}

\author{
Stefan Gilg ${ }^{1,2} \cdot$ Ernesto Sparrelid $^{1,2} \cdot$ Bengt Isaksson $^{1,2} \cdot$ Lars Lundell $^{1,2}$ • \\ Greg Nowak $^{1,3}$ - Cecilia Strömberg ${ }^{1,2}$
}

Received: 24 May 2016 / Accepted: 8 September 2016/Published online: 1 October 2016

(C) The Author(s) 2016. This article is published with open access at Springerlink.com

\begin{abstract}
Purpose The objectives of this study were to analyze the outcome after hepatectomy and to identify contributing factors to mortality and long-term survival in a population-based setting.

Method A retrospective, nationwide register study was performed. All patients who underwent hepatectomy in Sweden between 2002 and 2011 were identified in the Swedish Hospital Discharge Registry using their unique personal identification numbers. This cohort was linked to the National Cancer Registry (cancer diagnosis), the National Registry of Causes of Death, and the Migration Registry. Survival analysis by Kaplan-Meier method was performed to assess longterm outcome. A Cox regression model was used to analyze risk factors affecting long-term survival.

Results Overall, 4460 hepatectomies were performed. The 30- and 90-day mortalities were 1.8 and $3.1 \%$, respectively. The overall 5- and 10-year survival rates for all diagnoses were 45 and $38 \%$, respectively. Independent risk factors for 5-year mortality were as follows: patient age, comorbidity, male gender, intrahepatic/extrahepatic cholangiocarcinoma, gallbladder cancer, extent of hepatectomy, and hepatectomies performed at non-university hospitals. Re-resection (78.1\%
\end{abstract}

Stefan Gilg

stefan.gilg@ki.se

1 Institution for Clinical Science, Intervention and Technology (CLINTEC), Karolinska Institutet, Solna, Sweden

2 Department of Surgery at Centre for Digestive Diseases, Karolinska University Hospital, Stockholm, Sweden

3 Department of Transplantation Surgery, Karolinska University Hospital, Stockholm, Sweden with diagnosis "metastasis") was performed on 374 patients. In these patients, mortality risk decreased by $>50 \%$ (HR 0.42 ; $95 \%$, CI 0.33-0.53).

Conclusion In a population-based analysis, liver resections are done with a low mortality risk and good long-term outcome. Patients who underwent resection at a University Hospital showed a significant better outcome compared to patients resected at non-University Hospitals. These results support further centralization of liver surgery. Re-resection should be performed if feasible.

Keywords Hepatectomy $\cdot$ Outcome $\cdot$ Long-term survival · Risk factors · Population based

\section{Introduction}

During the last 20 years, liver surgery has undergone substantial changes mainly due to technical and medical innovations and is considered to offer the best opportunity of cure in cases of primary as well as secondary liver tumors [1-4]. Accordingly, the number of hepatectomies carried out has been constantly growing concomitantly with a centralization of these procedures into high volume academic centers [5, 6]. A variety of factors have been identified as contributing to decreased postoperative mortality rates and improved longterm survival rates [7-10]. However, the current literature is biased by a predominance of single-institution studies emerging from highly specialized centers, and the results presented do not necessarily reflect population-based short- and longterm results [11-13]. Population-based studies on overall mortality and long-term survival after hepatectomy are sparse. Therefore, it is uncertain to which degree the implementation and dissemination of changes in liver surgery has had any impact on the general population. Mortality related to liver 
resections seems to be lower when performed at high-volume, academic centers compared to low-volume, non-academic centers [14, 15], and surgeon training has been found to be highly predictive for post-operative complications [16]. This was supported by a recently published population-based study where Farges and colleagues concluded that reported mortality figures in the literature probably underestimate the real mortality risk associated with liver resection when population-based data were carefully analyzed $[15,17]$.

In Sweden, population-based data are available for analyses on both short-term results as well as long-term survival after all surgical procedures by utilizing the national medical registries $[6,18]$. The objectives of the present study were to analyze both the incidence and which factors may have influenced the outcome of liver surgery in Sweden between 2002 and 2011.

\section{Patients and methods}

All patients who underwent hepatectomy in Sweden during a 10-year period (2002-2011) and have been registered in the Swedish Hospital Discharge Registry were included in this cohort study. This registry was founded in 1965 , and since 1987, it includes all in-hospital patient contacts; these can be traced through the patients' national registration number for identification. The register contains both medical data (e.g., diagnosis, comorbidity, and procedure code) and general patient-related data (e.g., age, sex) but no specific information of, e.g., patient medication. The National Cancer Registry was set up in 1957 and collects cancer-related data like tumor site, histological type of cancer, and date of diagnosis but no specific pathological data like resection margins or lymph node status. In addition, the Registry of Causes of Death contains the individuals' death certificates with information such as underlying disease and date of death. All registers are endorsed and maintained by the Swedish Board of Health and Welfare. For this specific study, we identified all patients by their unique national registration numbers in the Hospital Discharge Register while matching an in-hospital discharge procedure code for liver resection according to the Tenth Revision of the International Classification of Diseases and Procedures (ICD 10 codes JJB00, JJB10, JJB20, JJB30, JJB40, JJB50, JJB53, JJB60, JJB71, and JJB96). Then, the personal national registration number was used for crosslinkage with the Registry of Causes of Death to estimate postoperative as well as long-term survival outcomes, and the Registry of Domestic and International relocations was used for censoring in the event of a cohort member emigrating. The cohort was followed until December 31, 2011. A detailed description of the methods used in this study has been described elsewhere [19].
In the risk factor analysis, the variable age was categorized into quartiles: $\leq 54,55-63,64-71$, and $\geq 72$ years, with the study period divided into two 5 -year intervals. The individual patient's comorbidity was classified according to the Charlson score [20], modified due to the fact that almost all patients had a diagnosis of malignancy, which was excluded from the score. The respective variables were categorized into four groups: no comorbidity, Charlson score $1-2$, Charlson score $3-4$, and Charlson score $\geq 5$.

All liver resections, both open and laparoscopic, were subdivided into three groups: minor ( $\leq 2$ Couinaud segments), major (3-4 Couinaud segments), and extended ( $>4$ Couinaud segments). Biopsies, ablations, and de-roofing of liver cysts were excluded from the analysis. All identified patients were stratified for diagnosis as stated in the discharge record as a surrogate for the indication for surgery. Accordingly, we identified the following diagnoses: metastases (ICD10 code C78.7), hepatocellular cancer (HCC, ICD10-code C22.0), intrahepatic (ICC, ICD10-code C22.1) and extrahepatic bile duct cancer (ECC, ICD10-code C24.0), gallbladder cancer (GBC, ICD10-code C23.9), and others/unclear. The patients with unclear diagnoses were then cross-linked with the National Cancer Register and subsequently classified into the corresponding identified group. A diagnosis of colorectal cancer (ICD10-codes C18.0-C18.9, C19.9, C20.9) along with a procedure code for liver resection was analyzed separately. The remaining patients were categorized as either benign or indefinite diagnosis. Hospitals were categorized into non-university and university hospitals as well as high-volume ( $>300$ resections during the study period) and low-volume centers.

For the risk factor analysis, hospitals were categorized as high- and low-volume hospitals (cutoff 300 resections during the study period), as well as university and non-university hospitals (7 university, 33 non-university hospitals), respectively. The Regional Research Ethics Committee of Stockholm approved the study protocol (DN 2010/1872-31/2).

\section{Statistical analysis}

Several patients had surgical liver procedures registered at more than one time point, and each procedure was handled as a separate event. Data were calculated as means \pm standard deviations for continuous variables, and proportions for categorical variables. Long-term survival rates after liver resection were assessed by the Kaplan-Meier method.

Cox proportional hazard ratios (HRs) with $95 \%$ confidence intervals (CI) were used for univariable and multivariable assessments of the association between potential risk factors and the hazard; in other words, the risk of death of all causes with time-at-risk as the underlying timescale was used. Potential risk factors used in the regression modeling were categorized in order to facilitate the analyses. Introducing 
the variables stepwise into the multivariable regression model tested potential confounding effects, and the risk factors were also tested for possible statistical interactions. $P$ values $<0.050$ were considered to be statistically significant. Statistical analyses were performed using SPSS Version 20 for Windows (SPSS, Inc., Chicago, IL).

\section{Results}

During the study period, there was an increase in annual number of liver resections. In total, 4460 (2381 (53.4\%) female, $2079(46.6 \%)$ male) patients with a median age of 64 were submitted to hepatic surgery. Of these, 374 patients underwent re-resection. Hepatectomies were continuously performed in 40 hospitals over the entire study period. The proportion of liver resections performed in academic compared to non-academic units is shown in Fig. 1. The incidence of hepatic resections increased from 2.5 per 100,000 inhabitants in 2002 to 8.1 per 100,000 inhabitants in 2011. At the same time, the number of minor resections increased from $n=1013$ to $n=1832$, major resections from $n=479$ to $n=791$, and extended resections from $n=127$ to $n=218$, when comparing the first and second 5-year period. Major/extended hepatectomies were almost exclusively performed at academic hospitals $(96 \%$ during the first 5 -year period and $99 \%$ during the second 5-year period). Kaplan-Meier estimation revealed a significant better survival after minor resections as compared to major and extended resections (Fig. 2). Median post-operative hospital stay over the entire study period was 9 days after minor resection, 11 days after major resection, and 13 days after extended resection, with no difference between the two study periods. The 30- and 90-day mortality figures, stratified for the extent of liver resection, are shown in detail in Table 1. The overall 30- and 90-day mortality rates were 1.8 and $3.1 \%$, respectively. There was no significant difference of postoperative mortality comparing the first with the second study period. In contrast, a significant difference was observed after hepatectomy performed in a non-university compared to university hospitals. In non-university hospitals, the 30- and 90-day mortality was 3.8 and $6.6 \%$ and in university hospitals 1.6 and $2.8 \%$, respectively. The Kaplan-Meier estimation of survival after liver resection in non-university and university hospitals is shown in Fig. 3. In the majority of the cases (59\%), the indication for hepatic resection was liver metastasis $(n=2644)$. HCC was the diagnosis in $9 \%(n=393)$, GBC in $6 \%$ $(n=254)$, ICC in $3 \%(n=129)$, and ECC in $2 \%$ $(n=76)$. The remaining minor diagnosis groups were $2.5 \%$ bowel cancer (without "metastasis") $(n=110)$, $2 \%$ other liver malignancies $(n=61)$, and $10 \%$ other/

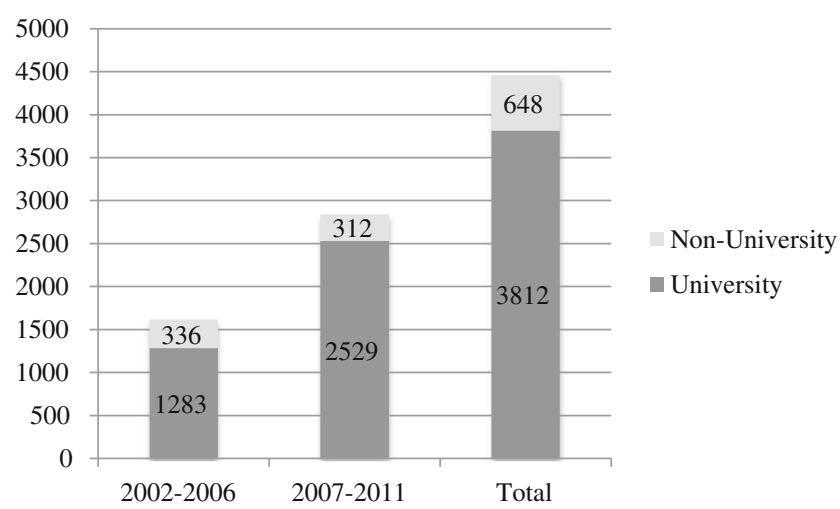

Fig. 1 Number of liver resections in university hospitals $(n=7)$ and nonuniversity hospitals $(n=33)$ in Sweden over the study period

unclear diagnosis $(n=452)$. Finally, about $8 \%$ of the cases were found to have a benign diagnosis $(n=341)$. The 5-year overall survival rate was $50 \%$ for the diagnosis "liver metastasis," $40 \%$ for HCC, $38 \%$ for GBC, $30 \%$ for ICC, and $20 \%$ for ECC. The related KaplanMeier estimation is shown in Fig. 4.

Metastatic liver disease was the reason for $78 \%$ of the reresections. For this group of patients, the survival rate was significantly better after a second resection compared to those patients with a single-resection only (Fig. 5).

Univariable and multivariable risk factor analysis for the long-term outcome after liver resection is shown in detail in Table 2. High age, comorbidity, as defined by a modified Charlson score (described in the "Methods" section), male gender, and hepatectomy performed outside a university hospital were identified as independent risk factors for death. Low hospital volume was identified as a risk factor in the univariable analysis, too, but was excluded in the multivariable analysis due to co-linearity with the status "university/ non-university hospital." Accordingly, the diagnoses ICC, $\mathrm{ECC}$, and $\mathrm{GBC}$ were identified as additional independent risk factors for death compared to patients with "liver metastasis" diagnosis. In addition, patients who underwent liver resection at non-university hospitals had a significantly decreased longterm survival rate compared with those who underwent surgery at university hospitals.

Table 1 Postoperative 30- and 90-day mortality specified for the extent of hepatectomy

\begin{tabular}{llll}
\hline Extent of resection & $\mathrm{n}$ & \multicolumn{2}{l}{ Mortality $\%$} \\
\cline { 3 - 4 } & & 30 days & 90 days \\
\hline Minor resections & $2845(63.8 \%)$ & 1.4 & 2.3 \\
Major resections & $1271(28.5 \%)$ & 2.1 & 3.2 \\
Extended resections & $344(7.7 \%)$ & 4.3 & 7.5 \\
\hline
\end{tabular}

Minor resections ( $\leq 2$ Couinaud segments), major resection (3-4 Couinaud segments), extended resection ( $>4$ Couinaud segments) 
Table 2 Univariable and multivariable (Cox) regression analysis of risk factors for mortality (long-term survival)

\begin{tabular}{|c|c|c|c|c|c|}
\hline & \multirow[t]{2}{*}{$n$} & \multicolumn{2}{|c|}{ Univariable analysis } & \multicolumn{2}{|c|}{ Multivariable analysis } \\
\hline & & $\mathrm{HR}(95 \% \mathrm{CI})$ & $P$ & $\mathrm{HR}(95 \% \mathrm{CI})$ & $P$ \\
\hline \multicolumn{6}{|l|}{ Demography } \\
\hline Age $\leq 54$ years & 1067 & 1.00 & & 1.00 & \\
\hline Age 55-63 years & 1143 & $1.39(1.19-1.61)$ & $<0.001$ & $1.16(0.99-1.35)$ & 0.061 \\
\hline Age $64-71$ years & 1226 & $1.90(1.65-2.20)$ & $<0.001$ & $1.55(1.34-1.79)$ & $<0.001$ \\
\hline Age $\geq 72$ years & 1024 & $2.43(2.11-2.80)$ & $<0.001$ & $1.90(1.64-2.22)$ & $<0.001$ \\
\hline Female sex & 2079 & 1.00 & & 1.00 & \\
\hline Male sex & 2381 & $1.20(1.09-1.32)$ & $<0.001$ & $1.11(1.01-1.22)$ & 0.037 \\
\hline \multicolumn{6}{|l|}{ Comorbidity } \\
\hline Charlson 0 & 3012 & 1.00 & & 1.00 & \\
\hline Charlson 1-2 & 1388 & $1.44(1.30-1.59)$ & $<0.001$ & $1.36(1.22-1.50)$ & $<0.001$ \\
\hline Charlson 3-4 & 39 & $1.90(1.26-2.87)$ & 0.002 & $1.83(1.20-2.78)$ & 0.005 \\
\hline Charlson $\geq 5$ & 21 & $3.23(1.90-5.47)$ & $<0.001$ & $3.06(1.80-5.21)$ & $<0.001$ \\
\hline \multicolumn{6}{|l|}{ Diagnosis } \\
\hline $\mathrm{CRCm}$ & 2644 & 1.00 & & 1.00 & \\
\hline $\mathrm{HCC}$ & 393 & $1.23(1.06-1.44)$ & 0.008 & $1.16(0.99-1.36)$ & 0.060 \\
\hline $\mathrm{ICC}$ & 129 & $1.78(1.41-2.25)$ & $<0.001$ & $1.76(1.38-2.23)$ & $<0.001$ \\
\hline $\mathrm{ECC}$ & 254 & $2.21(1.70-2.93)$ & $<0.001$ & $2.15(1.62-2.87)$ & $<0.001$ \\
\hline GBC & 76 & $1.42(1.19-1.70)$ & $<0.001$ & $1.53(1.27-1.85)$ & $<0.001$ \\
\hline $\mathrm{CRC}$ & 110 & $0.97(0.73-1.30)$ & 0.848 & $0.71(0.52-0.95)$ & 0.023 \\
\hline Other malignancy & 61 & $0.83(0.55-1.26)$ & 0.384 & $0.83(0.55-1.26)$ & 0.391 \\
\hline Benign & 341 & $0.15(0.10-0.22)$ & $<0.001$ & $0.19(0.13-0.28)$ & $<0.001$ \\
\hline Other & 452 & $0.68(0.57-0.81)$ & $<0.001$ & $0.74(0.62-0.88)$ & 0.001 \\
\hline \multicolumn{6}{|l|}{ Study period } \\
\hline 2002-2006 & 1619 & 1.00 & & & \\
\hline 2007-2011 & 2841 & $1.05(0.95-1.16)$ & 0.393 & & \\
\hline \multicolumn{6}{|l|}{ Extent of hepatectomy } \\
\hline Minor & 2845 & 1.00 & & 1.00 & \\
\hline Major & 1270 & $1.24(1.12-1.38)$ & $<0.001$ & $1.18(1.05-1.31)$ & 0.004 \\
\hline Extended & 345 & $1.64(1.40-1.92)$ & $<0.001$ & $1.10(1.28-1.78)$ & $<0.001$ \\
\hline \multicolumn{6}{|l|}{ Hospital volume } \\
\hline High volume & 3730 & 1.00 & & & \\
\hline Low volume & 730 & $1.17(1.05-1.32)$ & 0.008 & & \\
\hline \multicolumn{6}{|l|}{ Hospital structure } \\
\hline University hospital & 4096 & 1.00 & & 1.00 & \\
\hline Non-university uospital & 338 & $1.46(1.26-1.69)$ & $<0.001$ & $1.57(1.35-1.83)$ & $<0.001$ \\
\hline \multicolumn{6}{|l|}{ Re-resection } \\
\hline No & 4086 & 1.00 & & 1.00 & \\
\hline Yes & 374 & $0.40(0.31-0.50)$ & $<0.001$ & $0.44(0.34-0.56)$ & $<0.001$ \\
\hline
\end{tabular}

$H R$ hazard ratio, $95 \%$ CI $95 \%$ confidence interval, $C R C m$ colorectal cancer liver metastasis, $H C C$ hepato-cellular carcinoma, ICC intra-hepatic cholangiocarcinoma, ECC extra-hepatic cholangiocarcinoma $G B C$ gallbladder cancer, $C R C$ diagnosis of colorectal cancer coded for liver resection but without diagnosis "metastasis," other malignancy, other liver malignancies, other, other and unclear diagnosis

\section{Discussion}

The present study demonstrates that hepatectomy is a safe procedure and that related mortality was probably overestimated in previous, non-population-based studies. The extent of resection and primary liver cancers are independent risk factors for post-operative mortality. Re-resection of liver metastasis improved long-term survival significantly. On 


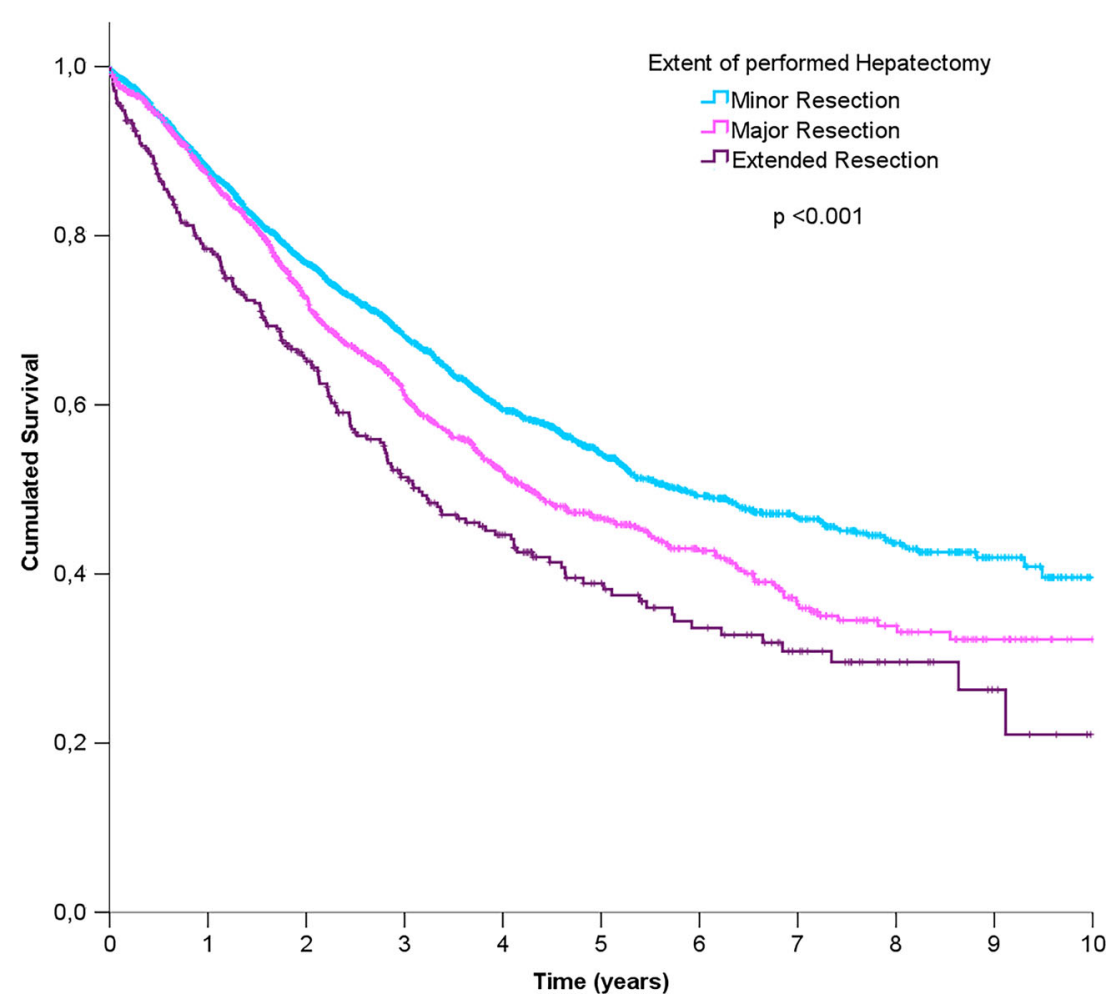

Fig. 2 Kaplan-Meier survival estimates for minor, major, and extended hepatectomy

the other hand, patients who underwent liver resections at non-university hospitals had a significantly worse outcome compared to those being resected at university hospitals.
The total number of hepatectomies in Sweden gradually increased during the study period (2002-2011). As expected, we observed huge differences in long-

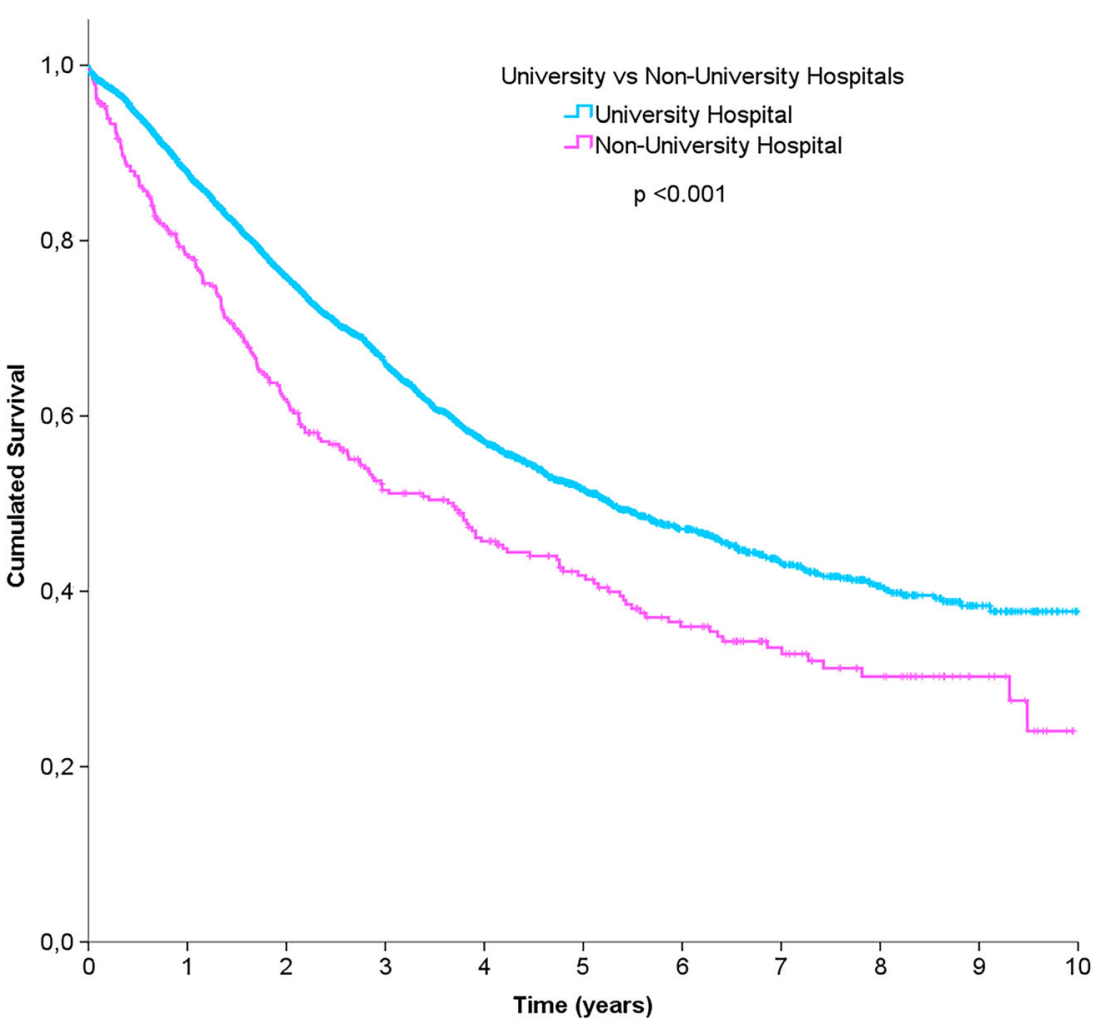

Fig. 3 Kaplan-Meier survival estimates for hepatectomies performed at university vs non-university hospitals 
Fig. 4 Kaplan-Meier surival estimates for different malign diagnosis

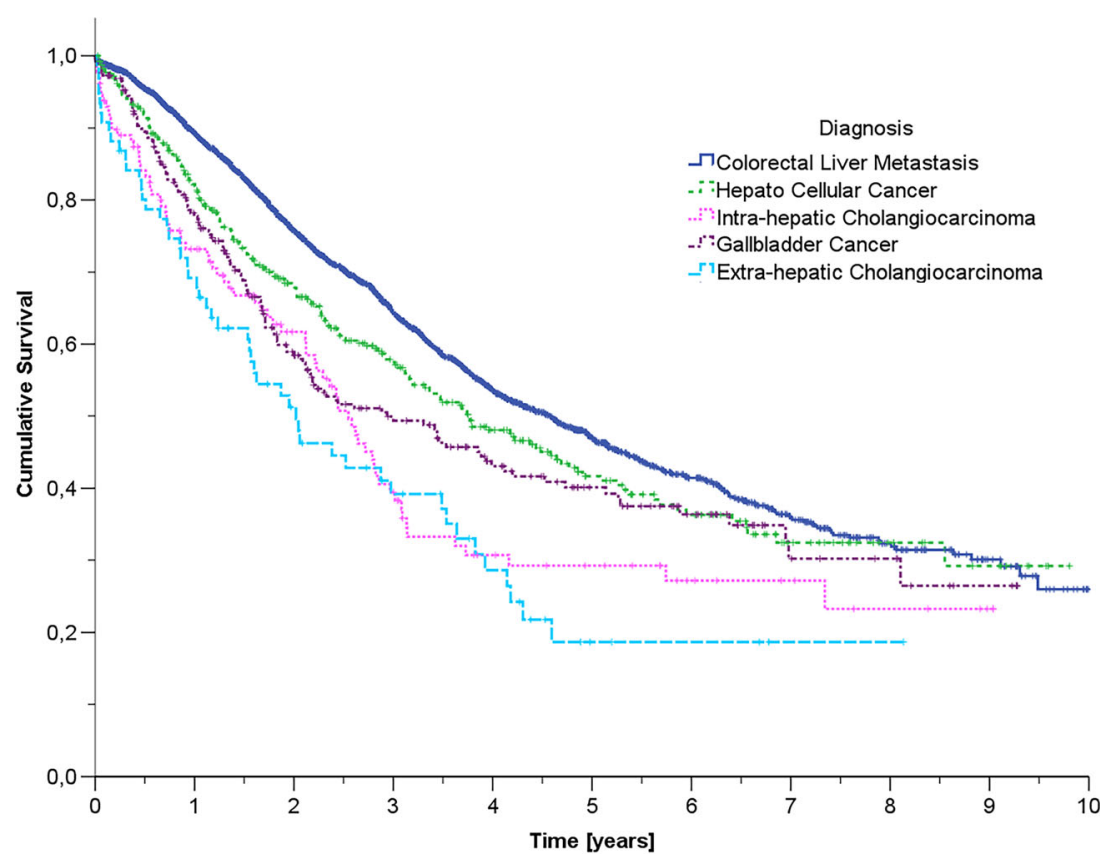

term outcomes depending on the underlying cancer diagnosis when adjusted for complementary risk factors like age and comorbidity, for example.

Previous publications addressing the outcome after liver surgery have mainly derived from single expert center experiences with a good chance of underestimating the risks and overestimating the results [15]. In Sweden, we have the opportunity to acquire medical information originating from the entire population with an almost complete follow-up using various national registries. An important methodological question
Fig. 5 Kaplan-Meier survival estimates for patients with single and more than one liver resection for metastatic disease

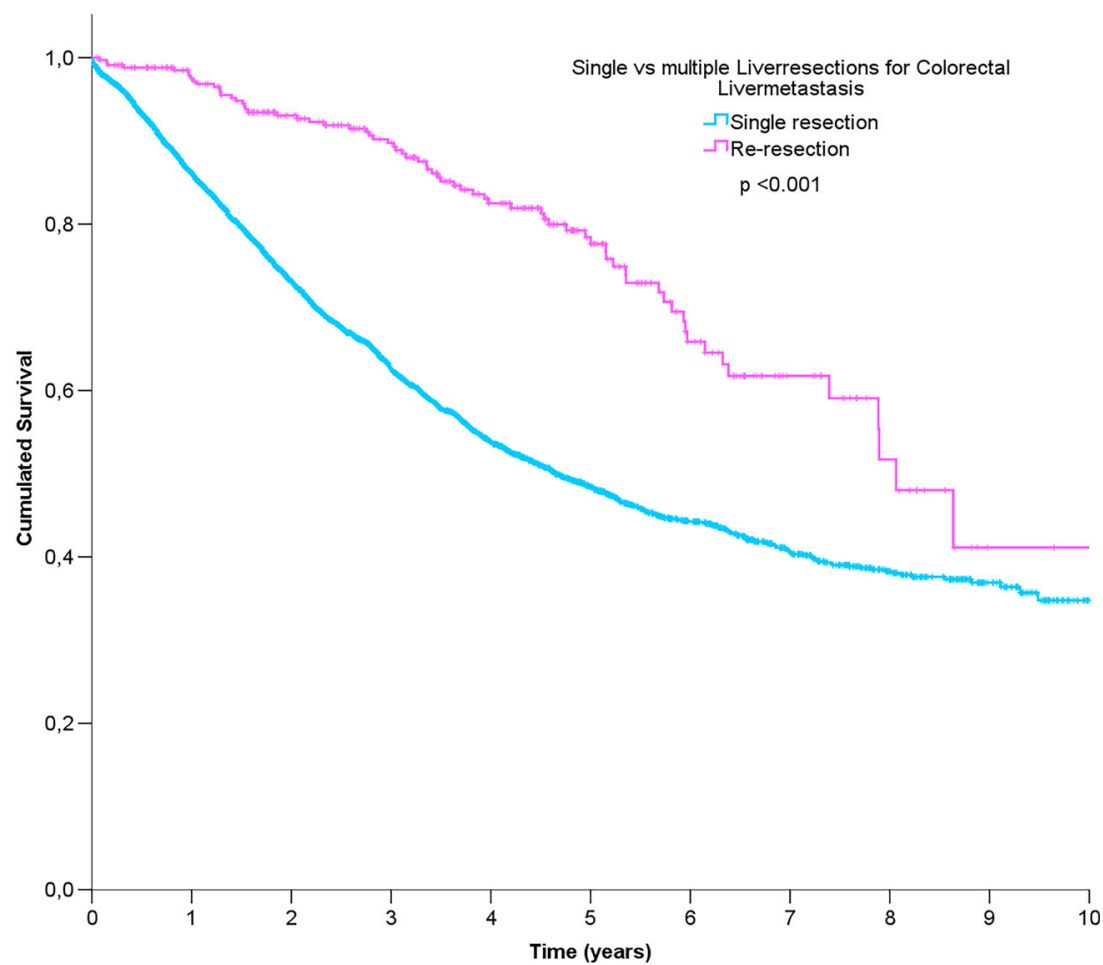


emerges regarding the validity of these registers since the quality of studies like this is totally dependent on data quality and coverage. Previous validation studies have reported a $95 \%$ accuracy concerning procedure codes in the Hospital Discharge Registry and a close to a $100 \%$ registration in the Registry of Causes for Death and National Cancer Registry, respectively [21]. Therefore, it can be concluded that the registries used for this study are reliable.

We were able to demonstrate a low postoperative mortality after hepatic surgery and, as expected, a significant difference in immediate post-operative outcomes depending on the extent of hepatic resection. The 90-day mortality rate was about twice that of the 30-day mortality rate, which confirms previous observations regarding the limited value of reporting 30 day mortality figures only [22]. However, the mortality figures in Sweden differ from those reported by Farges et al. [17], who studied the 30- and 90-day mortality risks after liver resection in France between 2007 and 2009, and found them to be 3.4 and $5.8 \%$, respectively. This could partly be explained by a lower incidence of liver resections in Sweden compared to France, implying a more conservative selection of patients. Furthermore, HCC was not analyzed separately in the French study. It is reasonable to assume that hepatectomies due to HCC are more common in France than in Sweden, where only $9 \%$ of all hepatectomies were performed for this indication. Moreover, in both countries, there might be a different case mix, too, that could influence the overall survival numbers. Despite an increase of major/extended liver resections of almost $100 \%$ in the second study period, the postoperative mortality figures remained unchanged. The most likely explanation behind this favorable development is that the increase in the number of complex hepatectomies was exclusively seen at high volume university hospitals and as many as $99 \%$ of major/extended hepatectomies were centralized to these units during the second study period. This development implies improved training of liver surgeons, something that has previously been reported as a major predictive factor for patient outcome after hepatectomy [5]. This conclusion is also supported by our finding that 30- and 90-day mortality is significantly higher for hepatectomies performed in low-volume, non-academic centers compared to university hospitals.

Regarding the long-term prognosis after surgery for primary and secondary liver cancers, we were able to define some independent risk factors for death. High age, severe comorbidity, and male gender were identified as patient-specific risk factors. Concerning the underlying cancer diagnosis, the highest risk of mortality was related to cholangiocarcinoma, gallbladder cancer, and hepatocellular cancer. In contrast, patients undergoing hepatectomy due to liver metastasis showed a significantly better 5 -year survival, confirming earlier reports $[8,14,23]$. The significantly higher short-term mortality and worse long-term outcome after liver surgery in nonacademic compared to academic units cannot be explained by, e.g., a higher frequency of synchronous procedures directed toward both the primary tumor and liver metastases but remained as an independent risk factor even in the multivariable analysis. Hence, it is tempting to speculate that surgeon/ staff training and less radical surgery are reasons behind these results. Undoubtedly, these data further support the ongoing trend of centralization of corresponding surgical procedures to high volume centers.

In addition, we observed a significant survival benefit for patients after re-resection for liver metastasis. With this, we were able to confirm earlier reports deriving from single institutions in a population-based setting [24-27]. Given the possible impact of the selection of patients undergoing re-resection, our data provides evidence to justify an aggressive surgical approach in the individual patient and support the conclusion made by Antoniou and co-workers that re-resection should be encouraged whenever possible and feasible [9].

\section{Conclusion}

In Sweden, liver surgery has expanded significantly during the last decade and is now practiced with a favorable postoperative risk profile. However, those with primary liver cancers still suffer a poor chance of long-term survival. Superior outcome of patients from University Hospitals support further centralization of liver surgery to high volume centers. In patients with liver metastases, re-resection should be performed if possible.

Author contribution All authors contributed to study conception and design, took part in the interpretation of data and critically revised the manuscript. S Gilg and C Strömberg were responsible for acquisition and primary analysis of the data. S Gilg, E Sparrelid, L Lundell, and C Strömberg drafted the manuscript.

\section{Compliance with ethical standards}

Ethical approval All procedures performed in studies involving human participants were in accordance with the ethical standards of the institutional and/or national research committee and with the 1964 Helsinki declaration and its later amendments or comparable ethical standards. This article does not contain any studies with animals performed by any of the authors. Informed consent was not applicable due to study design and ethical approval.

Conflict of interest The authors declare that they have no conflict of interest.

Data were partially communicated by an oral presentation during the IHPBA meeting in Seoul, South Korea, March 2014. 


\section{Appendix}

No. at risk

\begin{tabular}{lrrrrrr}
\hline Years & \multicolumn{1}{l}{0} & \multicolumn{1}{l}{2} & \multicolumn{1}{l}{4} & \multicolumn{1}{c}{8} & 10 \\
\hline Minor & 2845 & 1610 & 837 & 359 & 134 & 2 \\
Major & 1270 & 702 & 350 & 157 & 48 & 0 \\
Extended & 345 & 179 & 88 & 42 & 14 & 0 \\
\hline
\end{tabular}

No. at risk.

\begin{tabular}{|c|c|c|c|c|c|c|}
\hline Years & 0 & 2 & 4 & 6 & 8 & 10 \\
\hline University & 4096 & 2295 & 1160 & 490 & 164 & 2 \\
\hline Non-university & 364 & 196 & 115 & 68 & 32 & 0 \\
\hline
\end{tabular}

No. at risk.

\begin{tabular}{lrrrrrr}
\hline Years & \multicolumn{1}{l}{0} & \multicolumn{1}{c}{2} & \multicolumn{1}{l}{4} & \multicolumn{1}{c}{6} & 8 & 10 \\
\hline CRM & 2644 & 1453 & 676 & 248 & 74 & 2 \\
HCC & 393 & 213 & 105 & 51 & 13 & 0 \\
GBC & 254 & 120 & 63 & 31 & 10 & 0 \\
ICC & 129 & 57 & 22 & 11 & 5 & 0 \\
ECC & 76 & 31 & 13 & 3 & 1 & 0 \\
\hline
\end{tabular}

No. at risk.

\begin{tabular}{|c|c|c|c|c|c|c|}
\hline Years & 0 & 2 & 4 & 6 & 8 & 10 \\
\hline Single resection & 2380 & 1261 & 562 & 209 & 64 & 1 \\
\hline Re-do resection & 268 & 192 & 114 & 39 & 10 & 1 \\
\hline
\end{tabular}

Open Access This article is distributed under the terms of the Creative Commons Attribution 4.0 International License (http:// creativecommons.org/licenses/by/4.0/), which permits unrestricted use, distribution, and reproduction in any medium, provided you give appropriate credit to the original author(s) and the source, provide a link to the Creative Commons license, and indicate if changes were made.

\section{References}

1. Agrawal S, Belghiti J (2011) Oncologic resection for malignant tumors of the liver. Ann Surg Rev 253(4):656-665

2. Clavien PA (2006) Surgical techniques for liver resection. J Gastrointest Surg: Off J Soc Surg Aliment Tract 10(2):166-167

3. Clavien PA, Petrowsky H, DeOliveira ML, Graf R (2007) Strategies for safer liver surgery and partial liver transplantation.
N Engl J Med Res Support, NIH, Extramural Res Support, Non-US Gov't Rev 356(15):1545-1559

4. Stangl R, Altendorf-Hofmann A, Charnley RM, Scheele J (1994) Factors influencing the natural history of colorectal liver metastases. Lancet 343(8910):1405-1410

5. Dimick JB, Wainess RM, Cowan JA, Upchurch GR Jr, Knol JA, Colletti LM (2004) National trends in the use and outcomes of hepatic resection. J Am Coll Surg 199(1):31-38

6. Jersenius U, Granath F, Arvidsson D, Blomqvist P (2005) Liver operations in Sweden in 1987-99. Scand J Surg 94(1):25-30

7. Abbadi RA, Sadat U, Jah A, Praseedom RK, Jamieson NV, Cheow HK et al (2014) Improved long-term survival after resection of colorectal liver metastases following staging with FDG positron emission tomography. J Surg Oncol 110(3):313-319

8. Aloia TA, Fahy BN, Fischer CP, Jones SL, Duchini A, Galati J et al (2009) Predicting poor outcome following hepatectomy: analysis of 2313 hepatectomies in the NSQIP database. HPB (Oxford) 11(6): $510-515$

9. Antoniou A, Lovegrove RE, Tilney HS, Heriot AG, John TG, Rees $M$ et al (2007) Meta-analysis of clinical outcome after first and second liver resection for colorectal metastases. Surg Meta-Anal 141(1):9-18

10. Eppsteiner RW, Csikesz NG, Simons JP, Tseng JF, Shah SA (2008) High volume and outcome after liver resection: surgeon or center? J Gastrointest Surg: Off J Soc Surg Aliment Tract Res Support, NonUS Gov't 12(10):1709-1716 discussion 16

11. Belghiti J, Hiramatsu K, Benoist S, Massault P, Sauvanet A, Farges O (2000) Seven hundred forty-seven hepatectomies in the 1990s: an update to evaluate the actual risk of liver resection. J Am Coll Surg 191(1):38-46

12. Imamura H, Seyama Y, Kokudo N, Maema A, Sugawara Y, Sano K et al (2003) One thousand fifty-six hepatectomies without mortality in 8 years. Arch Surg 138(11):1198-1206 discussion 206

13. Jarnagin WR, Gonen M, Fong Y, DeMatteo RP, Ben-Porat L, Little $S$ et al (2002) Improvement in perioperative outcome after hepatic resection: analysis of 1,803 consecutive cases over the past decade. Ann Surg 236(4):397-406 discussion -7

14. McColl RJ, You X, Ghali WA, Kaplan G, Myers R, Dixon E (2008) Recent trends of hepatic resection in Canada: 1995-2004. J Gastrointest Surg: Off J Soc Surg Aliment Tract Comp Study Res Support, Non-US Gov't 12(11):1839-1846 discussion 46

15. Asiyanbola B, Chang D, Gleisner AL, Nathan H, Choti MA, Schulick RD et al (2008) Operative mortality after hepatic resection: are literature-based rates broadly applicable? J Gastrointest Surg: Off J Soc Surg Aliment Tract Res Support, NIH, Extramural Rev 12(5):842-851

16. McKay A, You I, Bigam D, Lafreniere R, Sutherland F, Ghali W et al (2008) Impact of surgeon training on outcomes after resective hepatic surgery. Ann Surg Oncol Res Support, Non-US Gov't 15(5):1348-1355

17. Farges O, Goutte N, Bendersky N, Falissard B (2012) Incidence and risks of liver resection: an all-inclusive French nationwide study. Ann Surg Res Support, Non-US Gov’t 256(5):697-704 discussion -5

18. Tornqvist B, Stromberg C, Persson G, Nilsson M (2012) Effect of intended intraoperative cholangiography and early detection of bile duct injury on survival after cholecystectomy: population based cohort study. BMJ 345:e6457

19. Stromberg C, Nilsson M (2011) Nationwide study of the treatment of common bile duct stones in Sweden between 1965 and 2009. Br J Surg 98(12):1766-1774

20. Charlson ME, Pompei P, Ales KL, MacKenzie CR (1987) A new method of classifying prognostic comorbidity in 
longitudinal studies: development and validation. J Chronic Dis 40(5):373-383

21. Ludvigsson JF, Andersson E, Ekbom A, Feychting M, Kim JL, Reuterwall C et al (2011) External review and validation of the Swedish national inpatient register. BMC Public Health Validation Stud 11:450

22. Mayo SC, Shore AD, Nathan H, Edil BH, Hirose K, Anders RA et al (2011) Refining the definition of perioperative mortality following hepatectomy using death within 90 days as the standard criterion. HPB: Off J Int Hepato Pancreat Biliary Assoc 13(7): 473-482

23. Groot Koerkamp B, Fong Y (2014) Outcomes in biliary malignancy. J Surg Oncol Rev 110(5):585-591
24. Adair RA, Young AL, Cockbain AJ, Malde D, Prasad KR, Lodge JP et al (2012) Repeat hepatic resection for colorectal liver metastases. Br J Surg 99(9):1278-1283

25. Shaw IM, Rees M, Welsh FK, Bygrave S, John TG (2006) Repeat hepatic resection for recurrent colorectal liver metastases is associated with favourable long-term survival. Br J Surg Eval Stud Res Support, Non-US Gov't 93(4):457-464

26. Thelen A, Jonas S, Benckert C, Schumacher G, Lopez-Hanninen E, Rudolph B et al (2007) Repeat liver resection for recurrent liver metastases from colorectal cancer. Eur J Surg Oncol 33(3):324-328

27. Wicherts DA, de Haas RJ, Salloum C, Andreani P, Pascal G, Sotirov D et al (2013) Repeat hepatectomy for recurrent colorectal metastases. Br J Surg Rev 100(6):808-818 